\title{
ASSENTAMENTO CAMPINA: A ORGANIZAÇÃO ESPACIAL EM CENÁRIOS DE TRANSFORMAÇÃO
}

\author{
Karina Araújo da Silva ${ }^{1}$
}

Valter Guimarães ${ }^{2}$

RESUMO: O assentamento Campina na Serra da Bodoquena em Mato Grosso do Sul tem enfrentado as limitações impostas pelo respeito aos espaços coletivos destinados a reserva legal, somando-se a isso o tamanho dos lotes e ainda a questão do abastecimento de água. Os resultados dessa pesquisa tiveram como objetivo organizar banco de dados relacionados ao meio físico, e formas de ocupação atual, envolvendo contatos constantes com os proprietários rurais (assentados) e com eles entender o dinamismo do ambiente. O conjunto desses resultados permitiu analises quanto ao espaço ocupado, com indicativos tanto da geologia, da topografia do relevo e espessura e movimentação de solos como subsídios a reflexão do uso sustentável da área. Comparando-se as características do meio físico com a forma de como os moradores vem utilizando a terra entende-se que a produção de subsistência ainda guarda relações harmoniosas com o ambiente, mas os avanços da atividade de criação de gado tem mostrado a falta de espaços equilibrados para tal pratica, pois encostas com declividades mais acentuadas tem sido desmatada e se transformado em espaços de pastagem, criando novas condições para as alterações estruturais do principal recurso natural disponível, os solos.

\footnotetext{
${ }^{1}$ Graduanda, acadêmica do Curso de Geografia- UFMS/CPAQ, araujo.karinna@hotmail.com.

${ }^{2}$ Doutor em Geografia, Professor associado-UFMS/CPAQ, vgeovalter@gmail.com.
} 
Palavras-Chave: Geografia regional. Espaço rural. Assentamento Campina.

\section{INTRODUÇÃO}

No Brasil, mais especificamente em Mato Grosso do Sul, uma parte significativa do quantitativo de municípios disponibilizou parcelas de suas terras no atendimento aos projetos de assentamento de famílias coordenado pelo instituto de colonização e reforma agraria - INCRA. Ao longo dos anos, os resultados divulgados têm mostrado uma realidade ora de euforia, quando recursos são investidos como incentivo a produção, ora, na maioria das vezes, de preocupações quanto ao sucesso futuro dos projetos. A questão da definição ou escolhas das áreas para os projetos de assentamentos nem sempre corresponde ao que se preconiza como "pedaço de chão para nele produzir". Exemplos existem e nesse trabalho usa-se como referencia projetos de assentamentos no município de Bodoquena, iniciando-se pelo assentamento Campina, distante aproximadamente em nove quilômetros da sede do município, com acesso pela rodovia MS-178, que liga Bodoquena a Bonito. Estas terras foram divididas em setenta e seis lotes totalizando $54,77 \%$ da área e, por se tratar de região de domínio topográfico serrano tem agrupada uma área de $43,57 \%$ de reserva legal/preservação, ficando 1,66\% ocupados com estradas vicinais e pequeno núcleo urbano (escola municipal).

Objetiva-se utilizar dos fundamentos da Geografia Regional no estudo da paisagem ocupada pelas atividades humanas, em suas relações de equilíbrio dinâmico. Concluída a etapa do levantamento de dados socioeconômicos, o objetivo foi o de conhecer o modo de vida das famílias, analisando dados relacionados à propriedade rural e à família. $\mathrm{A}$ pesquisa em termos de resultados futuros pretende conhecer a dinâmica do meio físico de forma sistêmica, correlacionando suas características com as das potencialidades e fragilidades, bem como contribuir com as perspectivas do aproveitamento agrícola para outras opções de geração de renda em consonância com os princípios da sustentabilidade ambiental. 


\subsection{CARACTERIZAÇÕES DA PLANTA GERAL DO PARCELAMENTO SOB A ÓTICA DA GEOGRAFIA REGIONAL}

O município de Bodoquena onde está inserida a área da pesquisa localiza-se na região sudoeste do estado de Mato Grosso do Sul e tem importância significativa no cenário produtivo nacional, destacando-se as atividades industriais da produção de cimento, calcário, e vem despontando na oferta de produtos turísticos principalmente pelas riquezas das suas belezas naturais.

\subsubsection{Condicionamentos do relevo}

Do ponto de vista geológico e geomorfológico na região da pesquisa dominam rochas calcarias de tonalidades cinza-escuros, às vezes cinza-claros sustentando uma extensa e estreita área serrana de natureza calco-dolomítico,geomorfologicamente conhecida como Serra da Bodoquena. Segundo Almeida (1965) A evolução do relevo nessa área serrana é talvez devido à natureza dolomítica da maior parte do planalto, além das constantes intercalações de camadas detríticas e argilosas nos dolomitos e calcários da Formação Cerradinho. 


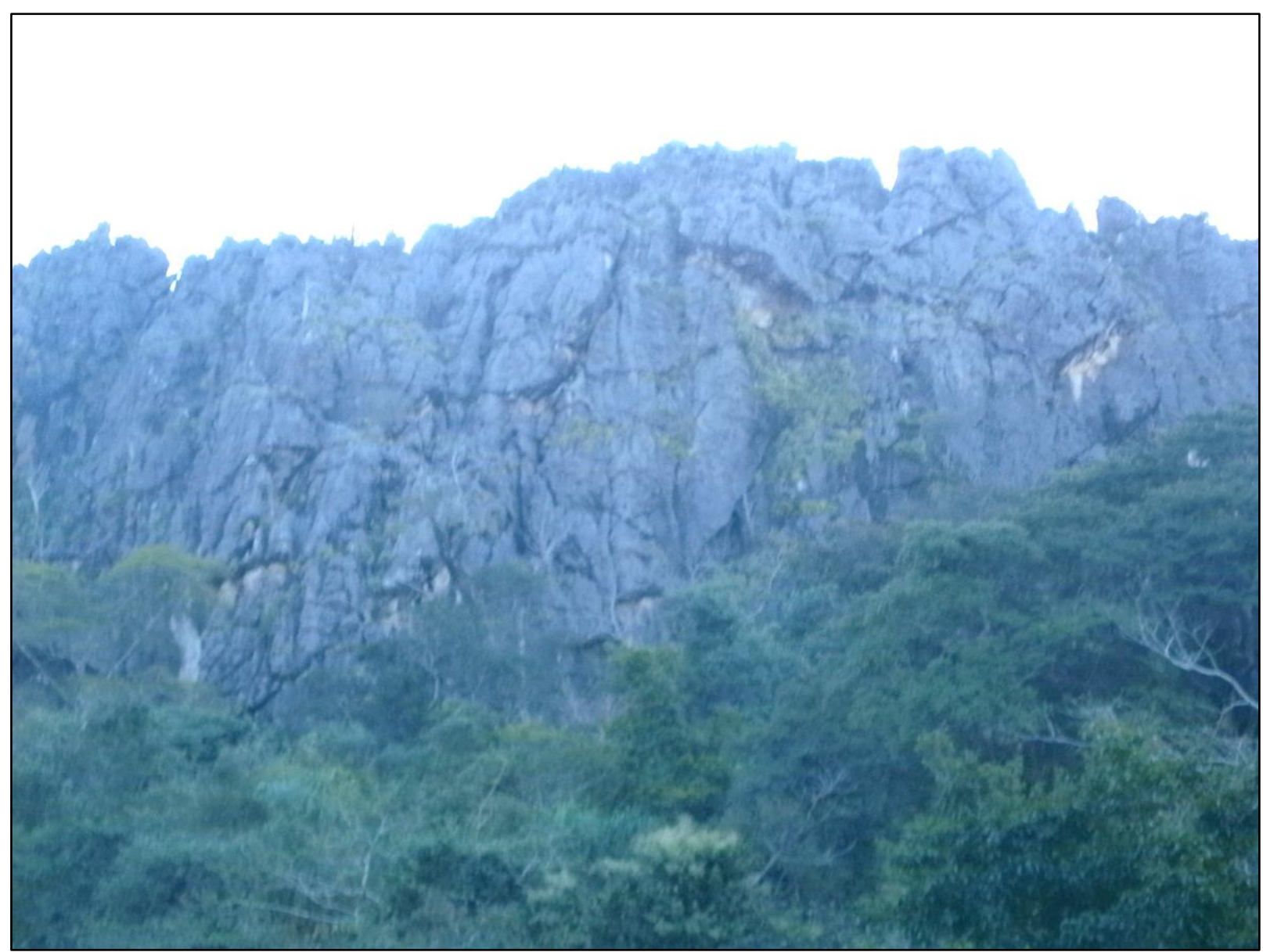

Figura 1. Assentamento Campina - Afloramento Calco-Dolomítico em escarpa serrana do Planalto da Bodoquena. Área representativa de reserva legal/preservação. (Fonte: Guimarães, 2012).

\subsubsection{Representatividade e usos da cobertura vegetal}

A vegetação merece destaque por se diferenciar muito das demais regiões, sendo nativa nas áreas de reserva na qual encontramos espécies arbóreas típicas de cerrado como, por exemplo, Angicos, Loros, Aroeiras, Ipês, Bocaiuvas, eTambori.

Estas são algumas das espécies que mais se destacam na região da Bodoquena, árvores protegidas pela lei e também de uso comercial, como por exemplo, Angicos e aroeiras são utilizados na fabricação de móveis rústicos, no caso da Acronomiaaculeata (bocaiuva) pode se extrair óleos para ser utilizados na fabricação de biodiesel, balas, e sorvetes, podendo também ser fabricada a farinha da polpa da fruta, existe também uma interessante história popular sobre o Tambori, esta, diz que a fruta da planta é prejudicial para o gado, podendo ser tóxica e abortiva. Segundo Justo (2000) "a combinação entre 
clima e solo favoreceu o desenvolvimento de vários tipos de vegetação, tais como floresta tropical, cerrado e campos limpos, além do complexo do Pantanal, bosques chaqueanos e floresta caducifólia".

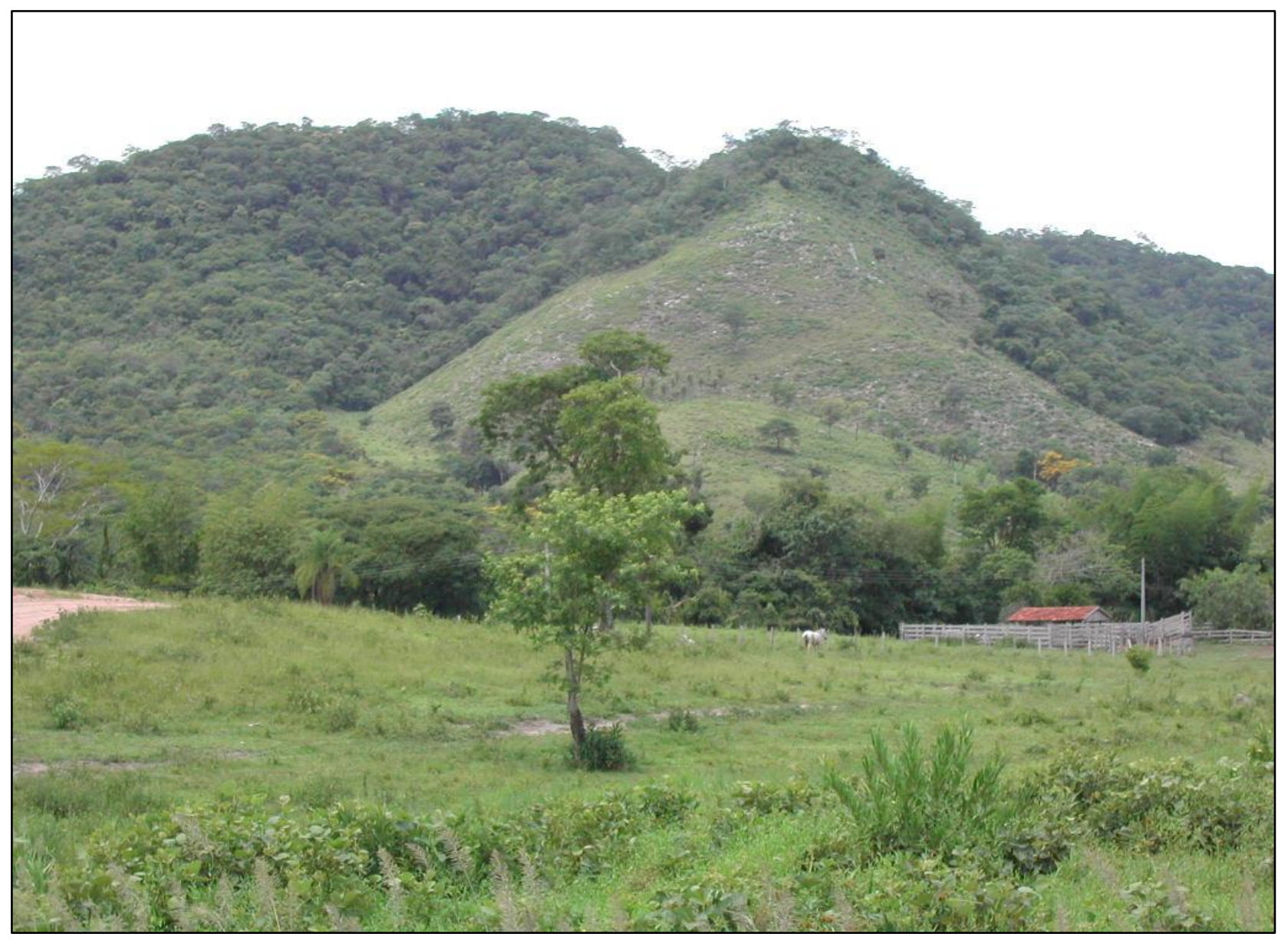

Figura 2. Assentamento Campina - Trecho de área de preservação, denunciando ocupação irregular da encosta com pastagem artificial. (Fonte: Guimarães, 2012).

\subsubsection{A Importância hidrográfica na divisão da topografia}

Do ponto de vista hidrológico as águas superficiais são controladas pelo nível de base do rio Miranda. Localmente esse mesmo nível é controlado pelo rio Salobra, com escalonamento topográfico em drenagem paralela de oeste para leste com os canais fluviais do córrego Escondido, córrego Campina e rio Betione. Grande parte da área do projeto de assentamento esta inserida na bacia hidrográfica do córrego Campina tanto em relação à área ocupada com lotes como aquela destinada a reserva legal/preservação.

Em direção ao divisor de aguas das bacias hidrográficas do córrego Campina e do córrego Escondido, onde estão distribuídos aproximadamente trinta lotes, os sistemas de 


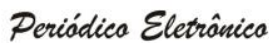

alimentação perene desses cursos fluviais estão representados dominantemente por canais subterrâneos, aparecendo ainda na base das encostas que culminam com os fundos de vales, algumas brotações de veios de água em superfície, conhecidas localmente como minas que outrora, quando da implantação do projeto de assentamento muitos servirão aos assentados, estando atualmente restritas a usos pelo gado. De maiorimportância tem sido as reservas de aguas subterrâneas, pois quase que a totalidade das propriedades vem sendo servido de abastecimento de agua através de poços semi-artesianos.

\subsubsection{Cobertura Pedológica}

Apesar dos indícios de riqueza como aptidão agrícola, os solos da região de estudo carecem de constante preocupação devido à pouca espessura média, em torno de quarenta centímetros além da facilidade de movimentação devido ao gradiente favorável das encostas os usos agrícolas tanto na produção de alimentos para o homem como para o gado tem mostrado sinais evidentes de deslocamentos encosta abaixo. Há ainda o agravante da substituição de faixas mais agressivas e menos propicias a usos agrícolas que vem tendo aos poucos a substituição da vegetação nativa por pastagem artificial. Segundo o levantamento semi-detalhado de solos do antigo sul de Mato Grosso a região pesquisada oferece dois tipos predominantes de solos cujas características vêm a seguir:

$\checkmark$ Associação complexa rendzina, textura argilosa ou média fase floresta caducifólia em relevo forte ondulado e montanhoso com muitos afloramentos de calcários + brunizem avermelhado de textura argilosa fase floresta subcaducifólia em relevo plano e suave ondulado.

$\checkmark$ Variações encontradas:

BrunizemAvermelhado intermediário para Terra Roxa Estruturada LatossólicaEutróficaem horizonte $A$ fraco ou proeminente em textura argilosa em fase floresta caducifólia de relevo suave ondulado e Brunizem Avermelhado intermediário para Vertisolcarbonático com horizonte A chernozênico de textura argilosa de fase floresta subcaducifólia em relevo plano. Brasil (1971)

Ainda aparecem pequenas áreas de Terra Roxa Estruturada LatossólicaEutrófica, com horizonte A fraco ou proeminente, de textura argilosa, fase floresta caducifólia de relevo suave ondulado, ou ondulado de regossol distrófico com horizonte A fraco, textura 
média muito cascalhenta, fase floresta caducifólia, de relevo ondulado, e, ainda, Regossoleutrófico de horizonte A fraco, textura média muito cascalhenta fase floresta caducifólia em relevo ondulado e forte ondulado.

\section{$\checkmark$ Litologia e material originário:}

Localizam-se os solos componentes desta Associação em áreas cujos embasamentos rochosos compreendem calcários, ardósias e filitos da formação Tamengo, grupo Corumbá, referido ao Cambro-Ordoviciano.

Particularmente, é o Brunizem Avermelhado proveniente de depósitos colúvioaluviais pseudo-autóctones dos materiais rochosos mencionados.

\section{$\checkmark$ Relevo e altitude:}

Localiza-se em relevo bastante movimentado, apresentando topografia variável, predominando, de modo geral, o relevo forte ondulado e montanhoso. As elevações são de topo pouco arredondado, com vertentes convexas ou convexo-côncavas de dezenas a centenas de metros, pequenos vales em $\mathrm{V}$ ou estreitos vales de fundo achatado. $\mathrm{A}$ Rendzina ocupa áreas de relevo mais movimentado, sendo o Brunizem Avermelhado encontrado nos fundos dos vales. As altitudes variam de 300 a 600 metros.

\section{$\checkmark$ Vegetação e uso atual:}

Considera-se a vegetação como primitiva ocupada por floresta caducifólia e subcaducifólia. O uso atual, leia-se1970, ocupado na maioria (aproximadamente 80\%) com vegetação natural e apenas pequena parcelas eram utilizadas para cultivos de subsistência, principalmente nas áreas de solos Brunizens Avermelhados.

$\checkmark$ Conceituação dos solos brunizens avermelhados:

Solos com sequencia de horizontes $A B C$, medianamente profundos, com horizonte A chernozênico e horizonte B textural.

São argilosos, saturação de bases alta, fertilidades naturais elevada, pouco ácidos e alcalinos, elevados teores de silte, altos valores de fósforo e principalmente domínio do Cálcio em $80 \%$ das bases trocáveis, de ligeiramente plástico e pegajoso a muito pegajoso quando molhado no horizonte $A$. 


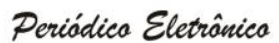 Fórum Ambiental}

da Alta Paulista

ISSN 1980-0827

Volume 9, Número 7, 2013

Expansão e

Produção Rural X Sustentabilidade

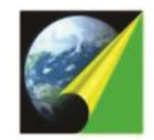

ANAP

Desenvolvidos a partir da deposição de materiais calcários, quartzitos, ardósias e filitos da formação Tamengo, contendo ainda dolomitos da formação Bocaina. Os perfis mais rasos foram identificados próximos a drenos e os mais profundos (fora do normal) estariam em transição para Terra Roxa Estruturada Latossólica.

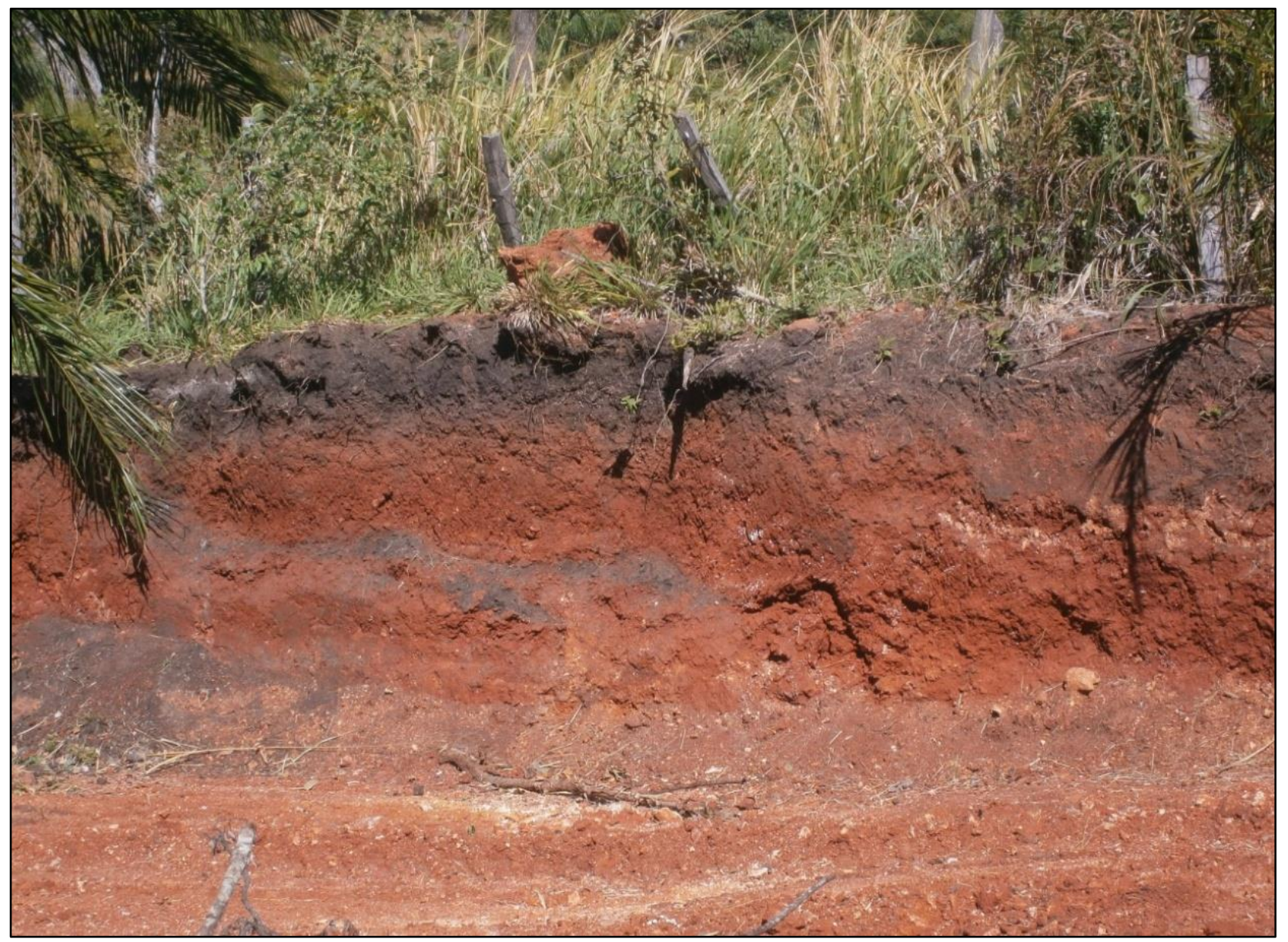

Figura 3. Assentamento Campina - Perfil de Solo Brunizem Avermelhado em Horizonte A Chernozênico. (Fonte: Guimarães, 2012).

\subsubsection{Referências Climáticas}

A região encontra-se submetida a um clima do tipo, Aw, segundo Galvão (1960 apud Justo2000), caracterizado por savanas tropicais, com verão úmido e inverno seco, com as precipitações anuais oscilando entre 1.000 a $2.000 \mathrm{~mm}$, concentradas entre os meses de outubro a abril e no restante do ano as chuvas são fracas e raras. As temperaturas médias mensais são superiores a $18^{\circ} \mathrm{C}$ e o mês mais quente é o que 
antecede ao período chuvoso. Em junho e julho ocorrem as temperaturas mais baixas, sendo comuns temperaturas mínimas absolutas inferiores a $0^{\circ} \mathrm{C}$ na Serra da Bodoquena.

Parra (2001) ao definir as regiões bioclimáticas do estado de Mato Grosso do Sul trabalhou e diagnosticou as relações de conforto humano por estação sazonal, identificando para a região em estudo condições de ambiente muito quente e abafado no verão; no outono variando de quente a confortável; no inverno dominantemente confortável e, na primavera dominantemente quente.

\section{COLETA E ANÁLISE DE DADOS PARA DIAGNÓSTICO SOCIOECONÔMICO}

Os trabalhos de coleta de dados a campo foram organizados com tópicos que pudessem fazer com que a equipe se utilizasse deles como referencial de dialogo objetivando o conhecimento da realidade daquele ambiente. Considerando tratar-se de uma região com indicadores de riscos à sustentabilidade, reforçadospelo reduzido tamanho das áreas das propriedades e o gradiente das encostas e porque não dizer também da maneira que o espaço vem sendo ocupado, tudo isso como elementos relevantes para o conhecimento da geografia regional.

O que se seguiu foi reunir a equipe e discutir com eles a importância da obtenção de informações de cada um dos tópicos arrolados como referencial de dialogo, dada a dependência delas para a formulação do diagnostico pretendido.

Cada propriedade visitada teve sua localização geográfica identificada e mapeada utilizando-se como mapa base para atividades de campo a carta planealtimétrica editada pela diretoria de serviço geográfico do exército, folha Campão, escala 1:100.000 e a plotagem dos pontos de localização das propriedades sobre base digital.A coleta parcial dos dados foi realizada no período de maio de 2012 a julho de 2013.

\subsection{Primeiros resultados analíticos do uso do espaço rural}

Das cinquenta e quatro propriedades visitadas, $1 / 3$ delas tem apenas dois moradores e 13\% delas tem apenas um morador. Assim 46\% das propriedades apresentam indicativos não comuns à ocupação de habitat rural. Buscando estabelecer uma relação entre numero de moradores com o numero de cômodos das casas, verificou- 
se que $91 \%$ das casas forneciam acomodações para no mínimo quatro e no máximo onze moradores. Percebe-se nessa comparação que fica evidente que o esvaziamento humano tem sido um indicador negativo na contextualização do processo de estabilização conhecido como permanência do homem no meio rural.

Outro resultado que chamou a atenção é que na maioria das propriedades procurase utilizar dos espaços para a produção de hortaliças e lavouras de feijão, milho além de fruticultura. Na cidade de Bodoquena a administração municipal disponibilizou espaço na área urbana para que os produtores rurais dos assentamentos viabilizassem a comercialização dos seus produtos, o que tem sido feito como "feirinha" aos sábados.

Por outro lado das informações obtidas há também resultados que ora contribui, ora podem se tornar motivos de preocupação aos moradores. Pelo menos em mais de $50 \%$ das propriedades não há apoio do governo com relação a recursos provenientes dos diferentes tipos de ajuda financeira, fator que se soma a uma problemática que vem se arrastando desde o inicio do processo de ocupação dos lotes que é o da dívida pra com o INCRA, pois cada propriedade é ciente de que a terra não foi cedida gratuitamente e do debito continua pendente naquele Órgão. Ainda considera-se o benefício do abastecimento de água encanada oriunda de poços semi-artesianos, condição necessária atualmente para que as famílias lá permaneçam. A maioria das propriedades não possui poço comum, uma vez que estão assentadas sobre terrenos afetados por orogenia de dobras assimétricas fragilizando a disponibilidade de reservas de águas e sustentação do nível do lençol freático a baixa profundidade.

Do ponto de vista de entendimento do relevo local pode- se dizer que a existência de atividade erosiva ainda não merece destaque apesar do domínio de topografia onde o gradiente de inclinação, este sim representando cuidados constantes no manejo das atividades agrícolas como um todo.

Outro quesito da conversa com os moradores demonstrou que todos estão cientes da existência de reserva legal e que este espaço é representado pela área serrana que exerce a função de divisor de águas entre o nível de base do canal do córrego Escondido, com o nível de base do canal do córrego Campina e divisor deste com o nível de base do canal do rio Betione. Trata-se então de área de reserva coletiva, visto que a maioria dos lotes possui área muito pequena para produtividade e fixação dos assentados no meio rural. 
Durante a visita às propriedades percebeu-se que a área do assentamento Campina é servida parcialmente pelas águas do canal do córrego Campina cujos principais alimentadores posicionam-se em trechos de topografia elevada ao sul da referida área. Este córrego devido a comportamentos de variação da altura do nível das águas ocorridas sucessivamente no período das chuvas marcou a topografia de forma a permitir, atualmente, o surgimento de pequenos braços condutores de águas, mas que não se distanciam muito do canal principal, pouco contribuindo e limitando o uso das águas naquele ambiente.

\section{CONCLUSÃO}

Revela-se tanto aos olhos do Observador como aos julgamentos dos resultados obtidos, que a paisagem apresenta, até então cenários de contemplação harmoniosa das relações entre o homem e o ambiente. Sinais de agressividade ainda pouco representam na escala de riscos. A distribuição espacial das propriedades rurais revela retratos de um lugar onde todas as possibilidades de avanços agressivos à Natureza começam a permitir a introdução de modelos que os resultados de outras pesquisas têm condenado, quais sejam o de permitir ao Homem sentir-se dono do espaço vivido, sem aprender q conviver com as necessidades naturais daquele espaço. Quaisquer caminhos dentro deste ambiente induzem a predizer que as perspectivas futuras podem tornar o Lugar insustentável as necessidades desse mesmo Homem.

\section{REFERÊNCIAS}

ALMEIDA, F. F. M. de. Geologia da Serra da Bodoquena (Mato Grosso). B. DNPM. Div. Geol. Miner., Rio de Janeiro, 1965.

BRASIL, M.A. Levantamento de reconhecimento dos solos do sul do estado de Mato Grosso. DNPA/DPP. Rio de Janeiro, 1971, 839 p, (Boletim Técnico, 18).

BRASIL, M. E. P. F. Instituto Nacional de Colonização e Reforma Agrária-INCRA. Planta Geral do Parcelamento da Gleba Campina em Bodoquena-MS. Escala 1:20000, Brasília, setembro de 1997. 
BRASIL, M. M. E. Diretoria de Serviço Geográfico. Restituição fotogramétrica. Vila Campão. Rio de Janeiro, 1973, Carta planealtimétrica, Color. $71 \mathrm{~cm}$ x $59 \mathrm{~cm}$. Escala 1:100.000. FOLHASF.21-X-A-IV.

CORRÊA, J. A. et al. Geologia das regiões centro e oeste de Mato Grosso do SulProjeto Bodoquena. Série Geologia Básica, no 3, M. M. E. DNPM/CPRM, Brasília, 1979, $111 \mathrm{p}$.

JUSTO, L. J. E. C. Fosfato da Serra da Bodoquena - Mato Grosso do Sul. M. M. E. CPRM. Projeto PIMA- GO/TO/MT/MS - Goiânia, 1999, 38 p.

PARRA, M. A. T. Regiões bioclimáticas do estado de Mato Grosso do Sul. Tese de doutorado. UNESP- IGCE, Rio Claro, 2001, 231 p. 